UDC 332.1

LBC 65.9

\title{
PROSPECTS OF THE REGIONAL INTEGRATION POLICY BASED ON CLUSTER FORMATION
}

\author{
Elena S. Tsepilova \\ Institute of Public Administration and Civil Service, Russian Presidential Academy of National Economy \\ and Public Administration, Moscow, Russian Federation \\ Olga I. Belyaeva \\ Institute of Public Administration and Civil Service, Russian Presidential Academy of National Economy \\ and Public Administration, Moscow, Russian Federation
}

\begin{abstract}
The purpose of this article is to develop the theoretical foundations of regional integration policy and to determine its prospects on the basis of cluster formation. The authors use such research methods as systematization, comparative and complex analysis, synthesis, statistical method.

Within the framework of the research, the concept of regional integration policy is specified, and its integration core - cluster - is allocated. The authors work out an algorithm of regional clustering, which will ensure the growth of economy and tax income. Measures have been proposed to optimize the organizational mechanism of interaction between the participants of the territorial cluster and the authorities that allow to ensure the effective functioning of clusters, including taxation clusters. Based on the results of studying the existing methods for assessing the effectiveness of cluster policy, the authors propose their own approach to evaluating the consequences of implementing the regional integration policy, according to which the list of quantitative and qualitative indicators is defined.

The present article systematizes the experience and results of the cluster policy of certain European countries, that made it possible to determine the prospects and synergetic effect from the development of clusters as an integration foundation of regional policy in the Russian Federation. The authors carry out the analysis of activity of cluster formations using the example of the Rostov region - a leader in the formation of conditions for the cluster policy development in the Southern Federal District. 11 clusters and cluster initiatives are developing in this region. As a result, the authors propose measures for support of the already existing clusters and creation of the new ones.

Key words: cluster, regional integration policy, cluster potential, cluster policy, integration core, taxation of clusters, tax revenues.
\end{abstract}

УДК 332.1

ББК 65.9

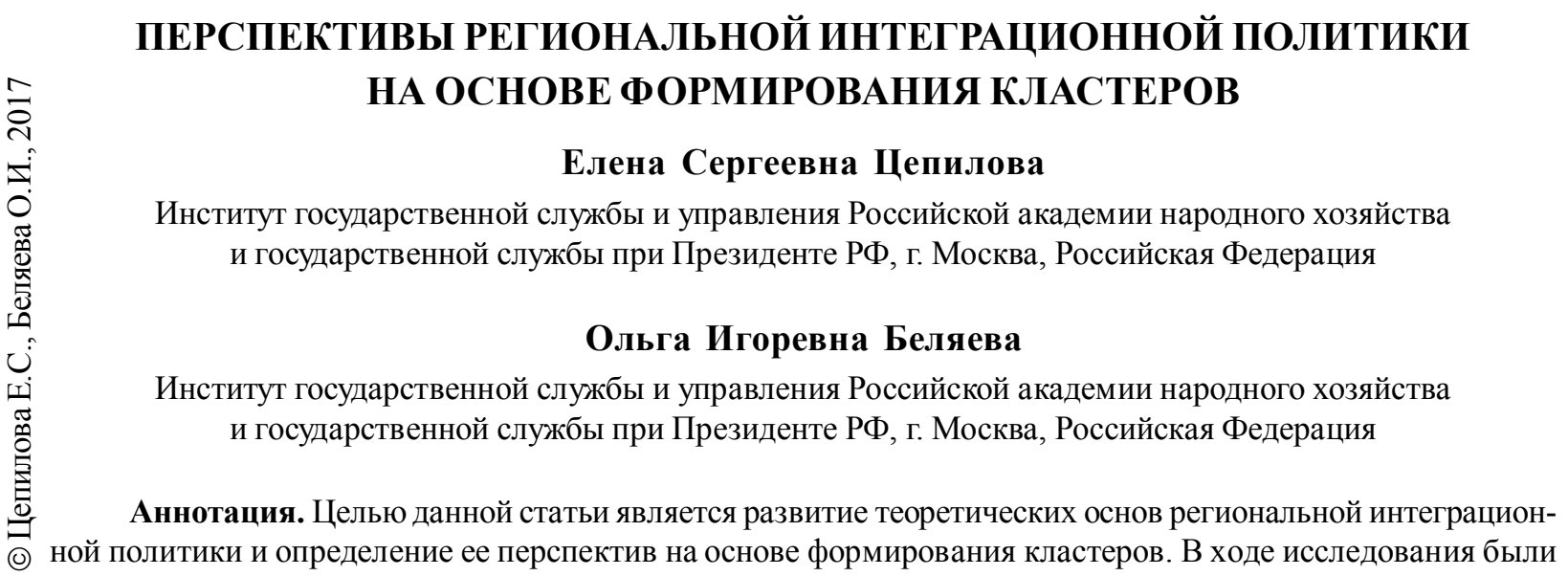




\section{МАКРОЭКОНОМИЧЕСКИЕ И ИНСТИТУЦИОНАЛЬНЫЕ УСЛОВИЯ}

использованы такие методы, как систематизация, сравнительный и комплексный анализ, синтез, статистический метод.

В рамках исследования уточнено понятие региональной интеграционной политики, в котором выделено интеграционное ядро - кластер. Разработан алгоритм региональной кластеризации, по итогам которого будет достигнут рост экономики и налоговых поступлений. Предложены меры по оптимизации организационного механизма взаимодействия между участниками территориального кластера и уровнями власти, позволяющие обеспечить эффективное функционирование кластеров, в том числе в отношении налогообложения кластеров. По итогам исследования существующих методов оценки эффективности кластерной политики предложен авторский подход к оценке последствий реализации региональной интеграционной политики, в соответствии с которым определен перечень количественных и качественных показателей.

В работе систематизирован опыт и результаты кластерной политики отдельных европейских стран, что позволило определить перспективы и синергетический эффект от развития кластеров как интеграционной опоры региональной политики в РФ. Проведен анализ работы кластерных формирований на примере лидера по формированию условий для применения кластерной политики в ЮФО - Ростовской области, в которой развиваются 11 кластеров и кластерных инициатив. В результате предложены меры по поддержанию уже действующих и созданию новых кластеров.

Ключевые слова: кластер, региональная интеграционная политика, кластерный потенциал, кластерная политика, интеграционное ядро, налогообложение кластеров, налоговые поступления.

Актуальность выбранной темы обусловлена тем, что развитие территориальных кластеров в России является одним из важнейших элементов региональной политики и условий повышения конкурентоспособности национальной экономики. Кластерные инициативы как эффективный механизм формирования и развития кооперационных проектов получили активное распространение в регионах нашей страны. В настоящее время применение кластерного подхода отчасти нашло отражение в стратегиях социально-экономического развития отдельных регионов и муниципальных образований в России. Однако вопросы региональной интеграционной политики, кластерного потенциала и аспекты организационного развития кластеров в научной литературе проработаны недостаточно глубоко.

Теоретические подходы к функционированию кластеров отражены в научных трудах М. Портера, М. Энрайта, С. Розенфельда, Т. Роланда, Ж. Мингалева, М. Афанасьева и др. Инновационные территориальные кластеры в РФ исследовали В.Л. Абашкин, С.В. Артемов, М.А. Гершман, Л.М. Гохберг и др. Отдельные вопросы теории, практики территориальных кластеров отражены в трудах Е.А. Черникова, М.Н. Власенко, О.А. Матвеевой, О.В. Гнеденковой, Р.М. Бурханова, К.Н. Савина и др. Вопросами налогообложения кластеров занимались В.Н. Засько, О.И. Донцова, М.А. Троянская, Ю.Г. Тюрина и др.
В настоящее время не существует единого унифицированного подхода к определению кластера. В трактовке М. Портера под кластером понимается «сконцентрированные по географическому признаку группы взаимосвязанных компаний, специализированных поставщиков услуг, фирм в соответствующих отраслях, а также связанных с их деятельностью организаций, например, университетов, агентств по стандартизации, а также торговых объединений в определенных областях, конкурирующих, но вместе с тем ведущих совместную работу» [7]. О.А. Матвеева в своем исследовании дает указание на наличие общей цели в элементах, входящих в кластер, за счет которых достигается синергетический эффект и кластер формируется как устойчивая система [6].

В мире существует большое многообразие видов кластеров. В научной литературе используют различные критерии их классификации, в основном по отраслевому принципу. Кластерный подход к региональному развитию носит характер стратегии повышения конкурентоспособности, что дает синергетический эффект от развития кластеров как интеграционной опоры региональной политики.

В настоящее время в России государственная региональная политика направлена на следующие векторы развития кластеров:

- поддержка совместных проектов участников кластеров вместо субсидирования отдельных предприятий; 
- поддержка кластеров в новых стартапах, возникающих индустриях, содействие их ориентации на поиски уникальных ниш на рынках будущего;

- усиление межкластерного взаимодействия, продвижение на внешние рынки;

- кластерное развитие все чаще применяется при разработке стратегий социальноэкономического развития территорий;

- смещение приоритетов с развития кластеров по отдельности в регионе к управлению портфелем кластеров, находящихся на разных стадиях развития;

- создание специальных инжиниринговых центров.

В научных источниках представлено много подходов к определению региональной политики. Одно из них закреплено в указе Президента РФ от 16.01.2017 № 13, в котором данный термин определяется как «система приоритетов, целей, задач, мер и действий федеральных органов государственной власти по политическому и социально-экономическому развитию субъектов РФ и муниципальных образований» [10]. В то время, как региональная интеграция - это форма развития, интеграционный процесс, включающий в себя наличие многих факторов и составляющих, происходящий в различных сферах (экономике, политике, социальной сфере) на макро- и микроуровнях. Этот процесс представляет собой развитие устойчивых экономических связей и разделение труда в региональной экономике, в котором синхронизируются хозяйственные взаимосвязи, происходит рост масштабов производства, образование новых региональных рынков и отраслей. А.Ю. Сироткин в своей работе обосновал, что «экономическая эффективность модернизации производственных систем в промышленности существенно возрастет при партнерской интеграции их деятельности, связанной с разработкой и внедрением высокотехнологичных продукции и проектов, предполагающей сохранение конкуренции между партнерами при объединении их стержневых компетенций» [15]. По мнению Е.А. Черникова, актуализируется вопрос создания кластеров «необходимостью перехода от вертикально-иерархических к горизонтально-сетевым формам организации производства, выступающих в качестве сетевых структур, позволяющих реа- лизовать возможность оперативного маневра ресурсами, ускорения введения инноваций, выхода на новые рынки, сокращения издержек» [18].

На основании анализа научной литературы понятие региональной интеграционной политики можно уточнить, как систему приоритетов, целей и задач федеральных, региональных органов власти по социально-экономическому развитию субъектов РФ и муниципальных образований, направленную на углубление экономических взаимосвязей и создание интеграционных объединений в различных сферах, в том числе на основе формирования кластеров, как регионального интеграционного ядра. Именно на основе интеграционных процессов государство в рамках промышленной политики разрабатывает федеральные и региональные отраслевые программы развития и социально-экономического развития регионов, где особое внимание уделяется приоритетным направлениям и реализации национальных проектов [14].

Интегральная эффективность производства и реализации продукции, а также конкурентоспособность территории определяется полнотой использования потенциала региональных и отраслевых секторов экономики. Территориальная близость обеспечивает сосредоточение разных видов территориальных потенциалов, совокупность которых во взаимодействии дает синергетический эффект, образуя кластерный потенциал региона (см. рисунок).

Без комплекса мер по укреплению промышленного потенциала субъектов РФ, включая действия по повышению инвестиционной привлекательности, формированию и совершенствованию кластеров, стимулированию региональных точек роста, невозможно достичь эффективной реализации стратегий социально-экономического развития регионов. Развитие кластерных образований в нашей стране направлено на территории, обладающие наибольшим потенциалом развития, и определяется программой поддержки пилотных инновационных территориальных кластеров, которая предусматривает следующие формы поддержки:

- выделение субсидий из федерального бюджета в целях софинансирования реализации программ развития кластеров; 


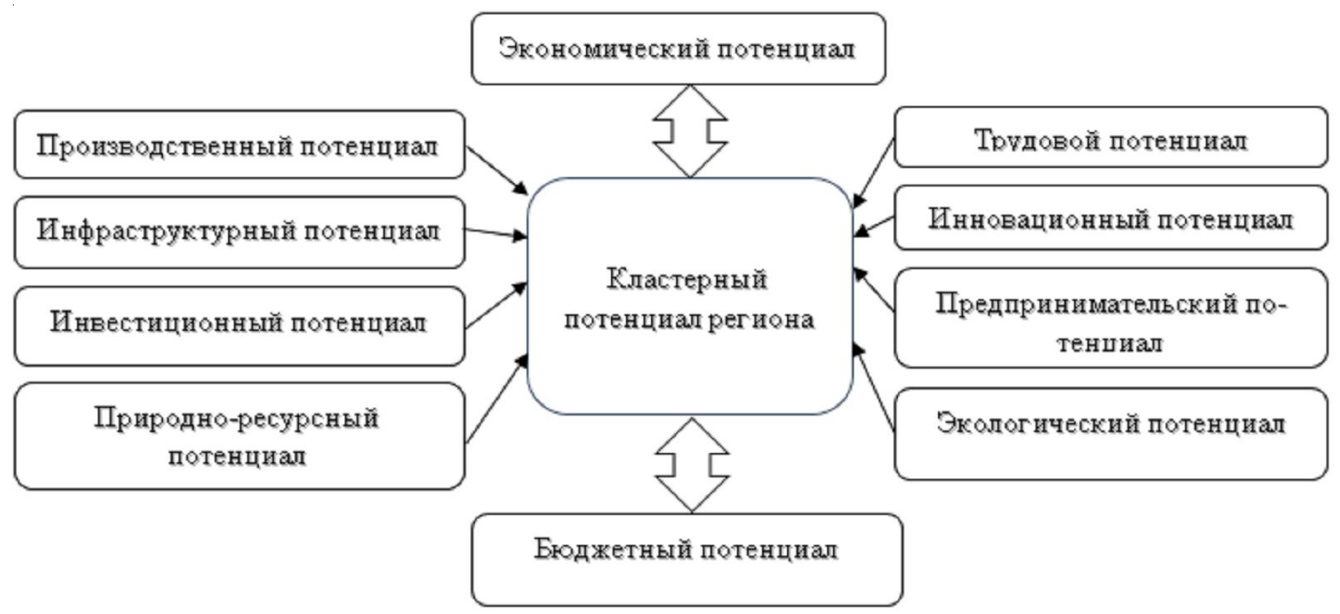

Рисунок. Модель формирования кластерного потенциала региона

Примечание. Составлено авторами.

- поддержка НИОКР;

- инвестиции в инфраструктуру;

- развитие инновационной инфраструктуры (технопарки, программа поддержки МСП, наноцентры, центры инжиниринга);

- поддержка «потока проектов»;

- развитие компетенций (Президентские программы подготовки управленческих кадров);

- содействие развитию международного сотрудничества и др.

В настоящее время в реестре российской кластерной обсерватории насчитывается 109 кластеров разной направленности (авиастроение, автомобилестроение, фармацевтика, новые продукты, информационно-коммуникационные технологии, космическая и медицинская промышленность, металлургия, металлообработка, микроэлектроника и приборостроение, оборонная промышленность, биотехнологии, сельское хозяйство, туризм и др.) [13]. Европейский опыт показывает большое распространение агропромышленных кластеров, что в условиях действующего продуктового эмбарго было бы перспективным для нашей страны (в РФ только 3 кластера по данному направлению).

Из общего числа зарегистрированных кластеров на высоком уровне организационного развития находится 7,3\%, на среднем $12,8 \%$ и большинство на начальном $-79,8 \%$. По объему привлеченных внебюджетных инвестиций с большим отрывом лидирует Камский инновационный территориально-производ- ственный кластер Республики Татарстан (более 109 млрд руб.). Можно выделить консорциум инновационных кластеров Московской области и инновационный кластер Ульяновской области (более 10 млрд руб.). Кластеры Красноярского края, Самарской и Ульяновской областей демонстрируют темпы прироста на уровне 27-30 \%. В 2016 г. в кластерахлидерах насчитывалось 175 технологических стартапов. В настоящий момент около $60 \%$ подобных компаний сформированы в Нефтехимическом территориальном кластере Республики Башкортостан и Консорциуме инновационных кластеров Московской области. В каждом из остальных инновационных кластеров их не более 15 [4]. В таблице 1 представлен анализ существующих кластеров в РФ по численности работников.

К примеру, в Южном федеральном округе лидерами по формированию условий для применения кластерной политики являются Ростовская и Волгоградская области, в то время как Краснодарский край и Астраханская область имеют более низкий потенциал формирования и развития кластеров. Среди регионов ЮФО лидером является Ростовская область (32-е место), Волгоградская область занимает среднее положение (47-е место), при этом опережая Астраханскую область (55-е место) и Краснодарский край (57-е место) [1, с. 145].

В Ростовской области в 2015 г. утверждена Концепция кластерного развития, согласно которой кластерная политика проводится в два этапа [5]: 
E.C. Цепилова, О.И. Беляева. Перспективы региональной интеграционной политики на основе кластеров

Таблица 1

Анализ существующих кластеров в РФ по численности работников

\begin{tabular}{|l|c|c|c|c|c|c|c|c|c|c|c|}
\hline \multirow{2}{*}{ Критерий } & \multicolumn{8}{|c|}{ Численность работаюих, чел. } & \multirow{2}{*}{ Итого } \\
\cline { 2 - 11 } & до 1000 & $\begin{array}{c}1000- \\
4000\end{array}$ & $\begin{array}{c}4000- \\
7000\end{array}$ & $\begin{array}{c}7000- \\
10000\end{array}$ & $\begin{array}{c}10000- \\
20000\end{array}$ & $\begin{array}{c}20000- \\
30000\end{array}$ & $\begin{array}{c}30000- \\
40000\end{array}$ & $\begin{array}{c}40000- \\
58000\end{array}$ & $\begin{array}{c}\text { свыше } \\
150000\end{array}$ & 109 \\
\hline $\begin{array}{l}\text { Число кластеров, } \\
\text { шт. }\end{array}$ & 15 & 24 & 16 & 12 & 13 & 15 & 7 & 6 & 1 & 109 \\
\hline $\begin{array}{l}\text { Процент к итогу, } \\
\%\end{array}$ & 13,8 & 22 & 14,7 & 11 & 11,9 & 13,7 & 6,4 & 5,5 & 0,9 & 100 \\
\hline
\end{tabular}

Примечание. Составлено авторами по данным Российской кластерной обсерватории.

- первый (2015-2017 гг.) предполагал совершенствование нормативной правовой базы, содействие специализированным организациям в разработке программ, привлечение бюджетного и внебюджетного финансирования и т. д.;

- второй этап (2018-2020 гг.) будет включать мероприятия, направленные на формирование благоприятных экономических и правовых условий для дальнейшего развития кластеров, в том числе: снижение административных барьеров и создание системы налогового стимулирования. Ответственным органом за реализацию политики является департамент инвестиций и предпринимательства Ростовской области, организационно-методическую, информационно-аналитическую и консультационную поддержку обеспечивает Центр кластерного развития региона.

Всего до 2020 г., по планам властей региона, планировалось создать: не менее 25 новых кластеров с участием как минимум 150 предприятий с 12 тыс. новыми рабочими местами, которые обеспечили бы ежегодный прирост совокупной выручки от продаж на внешнем рынке на $5 \%$; планируемый объем инвестиций 25,5 млрд руб. за пять лет.; совокупный объем отгруженных товаров, работ и услуг, выполненных собственными силами предприятий и организаций-участников кластеров, в действующих ценах - более 370 млрд рублей [5].

В настоящее время в Ростовской области развиваются 11 кластеров и кластерных инициатив [12]:

1. Инновационно-технологический кластер «Южное созвездие».

2. Инновационный территориальный кластер морского приборостроения «Морские системы».

3. Инновационный территориальный кластер станкостроения.
4. Инновационный кластер биотехнологий.

5. Инновационный территориальный кластер «Донские молочные продукты».

6 . Кластер информационно-коммуникационных технологий.

7. Винный территориальный кластер «Долина Дона».

8. Кластер сельхозмашиностроения.

9. Кластер «ЛегТексДон».

10. Волгодонский промышленный кластер атомного машиностроения.

11. Кластер вертолетостроения.

По состоянию на 01.05.2016 в состав территориальных кластеров входит около 300 хозяйствующих субъектов, включая субъекты малого и среднего предпринимательства, крупные промышленные предприятия, вузы, научно-исследовательские организации, региональные институты развития.

Основные мероприятия по развитию конкретных кластеров, состав участников, производственное, маркетинговое, кадровое направления роста кластеров определены в стратегиях развития шести приоритетных территориальных кластеров Ростовской области на 2016-2020 годы [11].

Обратимся к зарубежному опыту. Проведенный анализ кластерных инициатив РФ и зарубежных стран позволил констатировать, что в настоящее время процессами кластеризации охвачено более $50 \%$ экономик ведущих стран. Отдельные аспекты кластерной политики некоторых зарубежных стран представлены в таблице 2.

Европейская кластерная обсерватория (включает в себя картографирование, отчет о кластерных тенденциях, региональное табло с экосистемой, стресс-тест для самооценки) представляет собой интегрированную систему статистической информации, анализа 


\section{Особенности кластерной политики в РФ и зарубежных странах}

\begin{tabular}{|c|c|}
\hline $\begin{array}{c}\text { Страна (число } \\
\text { кластеров) }\end{array}$ & Особенности кластерной политики \\
\hline Россия (109) & $\begin{array}{l}\text { Создана российская кластерная обсерватория. Направления поддержки кластеров: } \\
\text { - выделение субсидий из федерального бюджета; } \\
\text { - поддержка НИОКР; } \\
\text { - инвестиции в инфраструктуру; } \\
\text { - развитие инновационной инфраструктуры (технопарки, программа поддержки МСП, } \\
\text { наноцентры, центры инжиниринга); } \\
\text { - поддержка «потока проектов»; } \\
\text { - развитие компетенций (Президентские программы подготовки управленческих кадров); } \\
\text { - содействие развитию международного сотрудничества кластеров и др. }\end{array}$ \\
\hline США (380) & $\begin{array}{l}\text { Создана высококонкурентная среда. Кластерный принцип построения экономики с } \\
\text { политикой низкого вмешательства государства, активное формирование рыночной среды. } \\
\text { Эффективная промышленная политика, направленная на стамулирование } \\
\text { предпринимательства и реализацию адресных программ поддержки. Имеются } \\
\text { высококвалифицированные, образованные и мобильные трудовые ресурсы }\end{array}$ \\
\hline Индия (106) & $\begin{array}{l}\text { Большую роль играют прямые иностранные инвестиции. Присутствует заимствование } \\
\text { технологий из других стран, идет опора на сильные институты. Активная государственная } \\
\text { политика в области стимулирования и развития кластеров }\end{array}$ \\
\hline Франция (96) & $\begin{array}{l}\text { Активная поддержка кластеров путем роста заработной платы, развития инфраструктуры, } \\
\text { обновления оборудования, обучение. Создается система сбора и обмена научн- } \\
\text { технической информации (в том числе бенчмаркинг) }\end{array}$ \\
\hline Германия (55) & $\begin{array}{l}\text { Крупнейшие корпорации играют ключевую роль в осуществлении глобальных инноваций. } \\
\text { Создают большое число рабочих мест и выступают в роли ядер инновационных кластеров, } \\
\text { взаимодействуя с университетами и организациями, занимающимися новейшими научными } \\
\text { исследованиями. Предусмотрено финансирование инновационных проектов. Разработка и } \\
\text { реализация стратегии маркетинга (позиционирования). Развитие новых моделей трансфера } \\
\text { знаний и технологий }\end{array}$ \\
\hline $\begin{array}{l}\text { Европейский } \\
\text { Союз (222) }\end{array}$ & $\begin{array}{l}\text { Создана Европейская кластерная обсерватория, в рамках которой действуют: } \\
\text { Европейская кластерная платформа сотрудничества, кластерные клубы, Европейское } \\
\text { стратегическое кластерное партнерство. Используют и внедряют методологию, } \\
\text { разработанную Европейской инициативой по повышению кластерного потенциала, в том } \\
\text { числе основанную на интеллектуальной специализации (смарт-технологии). Особое } \\
\text { внимание уделяется межсекторальным связям, интернационализации, а также } \\
\text { возможностям конкурентоспособности и предпринимательства в новых отраслях }\end{array}$ \\
\hline
\end{tabular}

Примечание. Составлено авторами по: [7].

и составления карт кластеров и кластерной политики в Европе [2]. Конечная цель заключается в оказании помощи государствамчленам и регионам в разработке смарт-специализаций и кластерных стратегий, в интеграции европейских кластерных политик и диалога заинтересованных лиц на высшем уровне.

Несмотря на существование многих исследований отечественных и зарубежных ученых, существует ряд вопросов, связанных с эффективностью организационно-экономического управления и деятельностью региональных кластеров. По итогам исследования существующих методов оценки эффективности кластерной политики предложен авторский вариант системы показателей для оценки последствий реализации региональной интегра- ционной политики по формированию кластеров, который определяется следующими показателями:

- объем привлеченных инвестиций в кластерные организации из средств внебюджетных источников;

- число вновь образованных кластеров;

- число патентов на изобретения;

- число внедренных технологических стартапов;

- численность работников в кластерных образованиях;

- увеличение числа отраслей ключевой специализации кластеров;

- рост объема работ и проектов в сфере НИОКР;

- рост числа кластеров с высоким уровнем организационного развития; 
- рост средней заработной платы работников организаций-участников;

- рост налоговых поступлений в бюджет региона в средне- и долгосрочной перспективе.

Формирование кластеров, как правило, пополняет налоговые поступления бюджета. Однако для того, чтобы кластер успешно развивался, необходимы налоговые послабления, что снижает в краткосрочном периоде доходы регионального бюджета (в основном речь идет о региональной части налога на прибыль, налоге на имущество организаций, земельном налоге). Помимо целей развития бизнеса в регионе, действующий налоговый механизм влияет на финансовую составляющую уровня жизни населения [8].

С целью стимулирования процесса кластеризации региональной экономики могут быть предусмотрены особые налоговые режимы для налогообложения кластерных образований. Одновременно кластеризация способствует борьбе с теневой экономикой, так как предприятия в составе кластера представляют крупного рыночного игрока и, соответственно, привлекают гораздо большее внимание со стороны контролирующих государственных органов, что сокращает возможности для теневого ведения бизнеса. Конфликт целей возникает в связи с тем, что, с одной стороны, для стимулирования кластерных инициатив государство заинтересовано в предоставлении кластерам налоговых льгот, но с другой стороны, предприятия в составе кластера приобретают гораздо большую рыночную власть и значительно повышают свою конкурентоспособность, поэтому предоставление им налоговых преференций может еще больше усилить их позиции в ущерб развития предприятий, не входящих в состав кластеров.

Кластеризация является направлением легализации доходов и отказа от теневого ведения бизнеса, поэтому ряд российских предприятий предпочитают не присоединяться к кластерным образованиям из-за опасений значительного увеличения налогового бремени в результате полного отражения своей хозяйственной деятельности в бухгалтерской и налоговой отчетности [16, с. 252]. Между тем выходом из этой ситуации видится применение опыта налогового контроля Франции - ди- агностические обзоры, цель которых - оценка рисков несоблюдения налогового законодательства и достоверности данных в учетных документах налогоплательщика. Сама процедура длится от 2 до 5 дней, и если инспектор решит, что степень риска недостаточна для более доскональной проверки, то диагностический обзор завершается $[17$, с. 70$]$.

По итогам анализа зарубежной практики и отечественного опыта реализации политики по формированию кластеров, предложены следующие меры по увеличению регионального кластерного потенциала:

- периодически проводить оценку эффективности, сопровождаемую политическими решениями для разработки региональной интеграционной политики в поддержку развития новых кластеров, разработки инновационных стратегий;

- усовершенствовать механизмы методической, информационной и образовательной поддержки развития кластеров, создать единую методологию сравнительного анализа и оценки кластерных организаций в целях улучшения процесса управления и определения потенциальных сфер для сотрудничества (межсекторального и трансграничного), создания кластерных консорциумов в поддержку новых отраслей;

- способствовать дальнейшему внедрению и совершенствованию инструмента бенчмаркинга, в том числе обмену лучшими практиками и опытом построения эффективного взаимодействия в кластерах, проведению обучения управляющего звена;

- обеспечить координацию усилий основных заинтересованных сторон по реализации интеграционной политики в регионе: органов власти, государственных структур, бизнесобъединений, кластерных организаций, НИИ, вузов, технопарков, бизнес-инкубаторов и др. Кластер формирует устойчивые отношения между элементами интеграционной политики, являясь интеграционным ядром;

- разрабатывать больше региональных инновационных стратегий, которые: помогут определить основные приоритеты для инвестиций в инновации; обеспечат предварительный анализ промышленных и кластерных возможностей и сопоставление сильных сторон территории с потребностями бизнеса; 
- развивать межкластерное взаимодействие (взаимное использование технологического оборудования, объектов инфраструктуры, продвижение продукции за рубеж, развитие управленческих компетенций);

- реализация комплекса мер по развитию рынка, конкуренции, основных и поддерживающих отраслей;

- поддерживать и внедрять механизмы государственно-частного партнерства и государственных преференций;

- введение государством системы дополнительных фискальных мер по налоговому стимулированию (в краткосрочном периоде из-за установления налоговых льгот снижается объем налоговых поступлений в государственный бюджет, в средне- и долгосрочном периоде благодаря развитию предпринимательства объем таких поступлений значительно возрастет).

Несомненно, что основными факторами успеха при развитии кластеров остаются спрос со стороны бизнеса, государственных заказчиков и иных заинтересованных структур [3, с. 43].

Таким образом, формирование кластерных образований в регионе будет способствовать активизации инновационной деятельности экономических субъектов, стимулировать технологический рост, поможет преодолеть экспортно-сырьевую ориентацию в производстве, а также повысит конкурентоспособность территорий. Установлено, что развитие интеграционных процессов в территориальной экономике на основе создания кластеров перспективно. В целях расширения числа предприятий-участников кластеров, повышения степени инновационности и минимизации издержек необходимо повышение эффективности региональной интеграционной политики на основе формирования кластеров и взаимодействия заинтересованных структур. На основе исследования существующей ситуации в регионах установлено, что трансформация региональной экономики требует интеграции потенциалов диверсифицированных направлений развития производства, что будет способствовать устойчивому развитию территорий.

Действующая налоговая система является определенным барьером кластеризации в России, так как присоединение к кластерам приводит к повышению открытости, про- зрачности и подотчетности бизнеса и увеличивает его налоговые расходы из-за невозможности продолжения вне правового поля; возрастают налоговые риски. С другой стороны, эти недостатки могут быть компенсированы введением пониженных налоговых ставок, упрощением форм отчетности, сокращением числа мероприятий государственного, в том числе налогового контроля для предприятий, входящих в кластер. Это будет способствовать дальнейшей кластеризации российской экономики.

\section{СПИСОК ЛИТЕРАТУРЫ}

1. Белоглазова, С. А. Оценка потенциала кластерообразования в регионах ЮФО / С. А. Белоглазова // Вестник Волгоградского государственного университета. Серия 3, Экономика. Экология. 2015. - №4 (33). - С. 138-149.

2. Европейская кластерная обсерватория. - Электрон. текстовые дан. - Режим доступа: http://clusterobservatory.eu (дата обращения: 15.06.2017). - Загл. с экрана.

3. Засько, В. Н. Льготное налогообложение кластеров в контексте формирования инновационной экономики России / В. Н. Засько, О. И. Донцова // Российское предпринимательство. - 2013. № 7 (229), апр. - С. 42-52.

4. Кластерная политика: достижение глобальной конкурентоспособности / В. Л. Абашкин, С. В. Артемов, Е. А. Исланкина [и др.] ; Мин-во экон. развития России, АО «РВК», НИУ «ВШЭ». - М. : НИУ «ВШЭ», 2017. - $324 \mathrm{c}$.

5. Концепция кластерного развития Ростовской области на 2015-2020 гг. : постановление Правительства РО от 12.03.2015 № 164. - Электрон. текстовые дан. - Режим доступа: http://www.donland.ru (дата обращения: 25.06.2017). - Загл. с экрана.

6. Матвеева, О. А. Формирование кластера как формы развития хозяйственных связей предпринимательских структур : автореф. дис. ... канд. экон. наук / Матвеева Ольга Александровна. - СПб., 2014. $-27 \mathrm{c}$.

7. Мировая экономика. Экономика стран и регионов : учеб. для академ. бакалавриата / В. П. Колесов [и др.] ; под ред. В. П. Колесова, М. Н. Осьмой. - М. : Юрайт, 2016. - 519 с.

8. Мытарева, Л. А. Налоговый механизм воздействия на финансовую составляющую уровня жизни россиян / Л. А. Мытарева // Вестник Волгоградского государственного университета. Серия 3, Экономика. Экология. - 2016. - № 4 (37). C. $155-164$. 
9. Об утверждении Концепции кластерного развития Ростовской области на 2015-2020 гг. : постановление Правительства РО от 12.03.2015 № 164. Электрон. текстовые дан. - Режим доступа: http: //www.donland.ru (дата обращения: 10.07.2017). Загл. с экрана.

10. Об утверждении основ государственной политики регионального развития Российской Федерации на период до 2025 г. : указ Президента Российской Федерации от 16.01.2017 № 13. - Электрон. текстовые дан. - Режим доступа: http:// rg.ru (дата обращения: 12.07.2017). - Загл. с экрана.

11. Об утверждении стратегий развития приоритетных территориальных кластеров Ростовской области на 2016-2020 гг. : постановление Правительства Ростовской области от 18.02.2016 № 104. - Электрон. текстовые дан. - Режим доступа: http://www. donland.ru (дата обращения: 03.07.2017). - Загл. с экрана.

12. О реализации кластерной политики в Ростовской области. - Электрон. текстовые дан. - Режим доступа: http:/www.donland.ru/economy/Klastery/ ?pageid=129174 (дата обращения: 11.07.2017). - Загл. с экрана.

13. Российская кластерная обсерватория.Электрон. текстовые дан. - Режим доступа: http:// cluster.hse.ru (дата обращения: 22.07.2017). - Загл. с экрана.

14. Савин, К. Н. Формирование и развитие регионального кластера качества жизнеобеспечения : автореф. дис. ... д-ра экон. наук / Савин Константин Николаевич. - Тамбов, 2009. - 46 с.

15. Сироткин, А. Ю. Модернизация производственных систем на основе создания организационно-экономического механизма интеграции промышленных высокотехнологичных предприятий : автореф. дис. ... канд. экон. наук / Сироткин Александр Юрьевич. - М., 2012. - 19 с.

16. Тюрина, Ю. Г. Кластеры в налогообложении: барьеры и стимулы / Ю. Г. Тюрина, М. А. Троянская // Экономика: вчера, сегодня, завтра. 2016. - № 3. - С. 251-259.

17. Цепилова, Е. С. Особенности налоговой системы и налогового контроля во Франции / Е. С. Цепилова // Финансы. - 2013. - № 2. - С. 68-71.

18. Черников, Е. А. Государственное регулирование кластера как экономической системы : автореф. дис. ... канд. экон. наук / Черников Евгений Александрович. - Саратов, 2010. - 22 с.

\section{REFERENCES}

1. Beloglazova S.A. Otsenka potentsiala klasteroobrazovaniya v regionakh YuFO [Assessment of the Potential of Cluster Formation in the Regions of the Southern Federal District]. Vestnik Volgogradskogo gosudarstvennogo universiteta. Seriya 3, Ekonomika. Ekologiya [Science Journal of Volgograd State University. Global Economic System], 2015, no. 4 (33), pp. 138-149.

2. Evropeyskaya klasternaya observatoriya [European Cluster Observatory (2017)]. URL: http:// clusterobservatory.eu. (accessed June 5, 2017)

3. Zasko V.N., Dontsova O.I. Lygotnoe nalogooblozhenie klasterov v kontekste formirovaniya innovatsionnoy ekonomiki Rossii [The Preferential Taxation of Clusters in the Context of the Formation of Innovative Economy of Russia]. Rossiyskoe predprinimatelstvo, 2013, no. 7 (229), pp. 42-52.

4. Abashkin V.L., Artemov S.V., Islankina E.A., et al. Klasternaya politika: dostizhenie globalnoy konkurentosposobnosti [Cluster Policy: Achieving Global Competitiveness]. Moscow, NIU VShE Publ., 2017. 324 p.

5. Kontseptsiya klasternogo razvitiya Rostovskoy oblasti na 2015-2020 gg.: postanovlenie Pravitelstva RO ot 12.03.2015 № 164 [The Concept of Cluster Development of the Rostov Region for 20152020: Resolution of the Government of March 12, 2015 no. 164]. URL: http:// http://www.donland.ru. (accessed June 25, 2017).

6. Matveeva O.A. Formirovanie klastera kak formy razvitiya khozyaystvennykh svyazey predprinimatelskikh struktur: avtoref. dis. ... kand. ekon. nauk [Formation of a Cluster as a Form of Development of Economic Relations of Business Structures. Dr. econ sci. diss.]. Saint Petersburg, 2014. $27 \mathrm{p}$.

7. Kolesov V.P., et al. Mirovaya ekonomika. Ekonomika stran i regionov: ucheb. dlya akadem. bakalavriata [World Economy. Economy of Countries and Regions: Textbook for Bachelor Students]. Moscow, Yurayt Publ., 2016. 519 p.

8. Mytareva L.A. Nalogovyy mekhanizm vozdeystviya na finansovuyu sostavlyayushchuyu urovnya zhizni rossiyan [Tax Mechanism of Impact on the Financial Component of the Living Standards of Russians]. Vestnik Volgogradskogo gosudarstvennogo universiteta. Seriya 3, Ekonomika. Ekologiya [Science Journal of Volgograd State University. Global Economic System], 2016, no. 4(37), pp. 155-164.

9. Ob utverzhdenii Kontseptsii klasternogo razvitiya Rostovskoy oblasti na 2015-2020 gg.: postanovlenie Pravitelstva RO ot 12.03.2015 № 164 [On Approval of the Concept of Cluster Development of the Rostov Region for 2015-2020: Resolution of the Government of March 12, 2015 no. 164]. URL: http: //www.donland.ru. (accessed July 10, 2017).

10. Ob utverzhdenii osnov gosudarstvennoy politiki regionalnogo razvitiya Rossiyskoy Federatsii na period do 2025 g.: ukaz Prezidenta Rossiyskoy 
Federatsii ot 16.01.2017 № 13 [On the Approval of the Foundations of the State Policy of Regional Development of the Russian Federation for the Period until 2025: the Decree of the President of the Russian Federation of November 16, 2017 no. 13]. URL: http:// www.rg.ru. (accessed July 12, 2017)

11. Ob utverzhdenii strategiy razvitiya prioritetnykh territorialnykh klasterov Rostovskoy oblasti na 2016-2020 gg.: postanovlenie Pravitelstva Rostovskoy oblasti ot 18.02.2016 № 104 [On the Approval of Strategies for the Development of Priority Territorial Clusters of the Rostov Region for 2016-2020: Resolution of the Government of the Rostov Region of February 18, 2016 no. 104]. URL: http://www. donland.ru. (accessed July 3, 2017).

12. O realizatsii klasternoy politiki v Rostovskoy oblasti [On the Implementation of Cluster Policy in the Rostov Region]. URL: http://www.donland.ru// economy/Klastery/?pageid=129174. (accessed July 11, 2017)

13. Rossiyskaya klasternaya observatoriya [Russian Cluster Observatory]. URL: http://www. donland.ru. (accessed July 22, 2017).

14. Savin K.N. Formirovanie $i$ razvitie regionalnogo klastera kachestva zhizneobespecheniya: avtoref. dis. ... d-ra ekon. nauk [Formation and Development of a Regional Cluster of Quality of Life Support. Dr. econ. sci. abs. diss.]. Tambov, 2009. 46 p.

15. Sirotkin A.Yu. Modernizatsiya proizvodstvennykh sistem na osnove sozdaniya organizatsionno-ekonomicheskogo mekhanizma integratsii promyshlennykh vysokotekhnologichnykh predpriyatiy: avtoref. dis. ... kand. ekon. nauk [Modernization of Production Systems Based on the Creation of an Organizational and Economic Mechanism for the Integration of Industrial High-Tech Enterprises. Dr. econ. sci. diss.]. Moscow, 2012.19 p.

16. Tyurina Yu.G., Troyanskaya M.A. Klastery v nalogooblozhenii: baryery i stimuly [Clusters in Taxation: Barriers and Incentives]. Ekonomika: vchera, segodnya, zavtra, 2016, no. 3, pp. 251-259.

17. Tsepilova E.S. Osobennosti nalogovoy sistemy i nalogovogo kontrolya vo Frantsii [Features of the Tax System and Tax Control in France]. Finansy, 2013, no. 2, pp. 68-71.

18. Chernikov E.A. Gosudarstvennoe regulirovanie klastera kak ekonomicheskoy sistemy: avtoref. dis. ... kand. ekon. nauk [State Regulation of the Cluster as an Economic System. Dr. econ. sci. abs. diss.]. Saratov, 2010. 22 p.

\section{Information about the Authors}

Elena S. Tsepilova, Doctor of Sciences (Economics), Associate Professor, Professor of Department of Regional Management, Institute of Public Administration and Civil Service, Russian Presidential Academy of National Economy and Public Administration, Prosp. Vernadskogo, 84, 119606 Moscow, Russian Federation, es.tsepilova@migsu.ru.

Olga I. Belyaeva, Candidate of Sciences (Economics), Associate Professor, Department of Regional Management, Institute of Public Administration and Civil Service, Russian Presidential Academy of National Economy and Public Administration, Prosp. Vernadskogo, 84, 119606 Moscow, Russian Federation, belyaeva_klgd@mail.ru.

\section{Информация об авторах}

Елена Сергеевна Цепилова, доктор экономических наук, доцент, профессор кафедры регионального управления, Институт государственной службы и управления Российской академии народного хозяйства и государственной службы при Президенте РФ, просп. Вернадского, 84, 119606 г. Москва, Российская Федерация, es.tsepilova@migsu.ru.

Ольга Игоревна Беляева, кандидат экономических наук, доцент кафедры регионального управления, Институт государственной службы и управления Российской академии народного хозяйства и государственной службы при Президенте РФ, просп. Вернадского, 84, 119606 г. Москва, Российская Федерация, belyaeva_klgd@mail.ru. 